\title{
PARTICIPIO PASIVO Y ARCAÍSMO EN EL DRAE (EDICIONES DE 1822 Y 1832)*
}

\author{
PASSIVE PARTICIPLE AND ARCHAISM IN THE DRAE \\ (1822 AND 1832 EDITIONS)
}

\author{
ENRIQUE JimÉNEZ RÍOS \\ Universidad de Salamanca \\ enrique@usal.es
}

Recibido: 30/11/2018

Aceptado: 14/02/2019

\begin{abstract}
Resumen
El artículo examina la supresión de participios pasivos en la sexta y séptima ediciones (1822 y 1832) del Diccionario de la lengua castellana de la Real Academia Española. La condición de variante gráfica, de arcaísmo y, sobre todo, de participio pasivo determina su eliminación en estas ediciones. Se aplica así una decisión lexicográfica de la que dan cuenta los prólogos respectivos. No obstante, como el participio puede ser usado como adjetivo (o sustantivo) y desarrollar acepciones propias de estas clases de palabras, se impone su mantenimiento en el diccionario, situación que la Academia resuelve de distinto modo desde el Diccionario de autoridades hasta hoy.
\end{abstract}

PALABRAS CLAVE: Participio, arcaísmo, diccionario, Real Academia Española

\begin{abstract}
This article examines the suppression of the passive participles in the sixth and seventh editions (1822 and 1832) of the Royal Spanish Academy's Dictionary of the Castilian Language. The condition of variant spelling, archaism and, above all, of passive participle determined their elimination from these editions. This is how the lexicographic decision explained in their respective prologues was implemented. However, since participles can be used as an adjective (or noum) and develop accepted meanings typical of these class of words, they should be kept in the dictionary, a situation that the Academy has resolved in a different way from the Diccionario de autoridades until today.

KEY WORDS: Participle, archaism, dictionary, Royal Spanish Academy
\end{abstract}

* Este artículo se enmarca en el proyecto de investigación "Historia interna del Diccionario de la Lengua Castellana de la RAE en el siglo XIX (1817-1852)" (FFI2014-51904-P), del Ministerio de Economía y Competitividad.

Para citar este artículo / To cite this article: Jiménez Ríos, Enrique (2019). Participio pasivo y arcaísmo en el DRAE (ediciones de 1822 y 1832). Azorín, Dolores; Clavería, Gloria y Jiménez Ríos, Enrique (Eds.): ELUA: El diccionario de la Academia y su tiempo: lexicografia, lengua y sociedad en la primera mitad del siglo XIX, Anexo V, págs. 233-251.

Enlace/Link: http://dx.doi.org/10.14198/ELUA2019.ANEXO5.10 


\section{INTRODUCCIÓN}

La conexión que se establece entre el participio y el adjetivo en el diccionario no es comparable a la que se da entre otras formas verbales y otras clases de palabras ${ }^{1}$. Y no lo es no tanto por la propia naturaleza del participio, clase de palabra ligada al adjetivo y al verbo por su forma y función (Bosque 1991: 168; Bargalló Escrivá 1996: 41; Hernando Cuadrado 2001: 90-91), cuanto por el hecho de que se inserta en el diccionario, se liga inmediatamente al verbo y se informa, si procede, de su uso como adjetivo (o sustantivo) (Alvar Ezquerra 1982 [1993]: 105). Y todo ello en una misma entrada lexicográfica. Esta inserción, y toda esta información, ha variado de acuerdo con el repertorio que lo ha documentado y el momento en que lo ha hecho.

A esto se une el distinto tratamiento lexicográfico que presentan los dos tipos de participios, pasivo y activo (o de presente) $)^{2}$ en el diccionario académico y en determinadas ediciones, porque el primero se marca como arcaísmo, si el verbo correspondiente también lo está (a excepción de los participios pasivos irregulares) ${ }^{3}$, y el segundo puede ser una voz arcaica independientemente de que lo sea el verbo; y porque aquel, en este diccionario, es eliminado en un momento de su historia y este es suprimido solo en algunos $\operatorname{casos}^{4}$. Esta última diferencia se debe al hecho de que el participio pasivo no se acompaña de definición - a menos que desarrolle un uso adjetival (o sustantivo), recogido como nueva acepción-y el activo siempre la presenta tras indicar su condición de participio.

Esta conexión entre participio — pasivo-, adjetivo/sustantivo y arcaísmo, que se acaba de presentar, la vamos a examinar a través de lo sucedido en dos ediciones concretas del Diccionario de la lengua castellana de la Real Academia Española, la sexta y séptima, publicadas en 1822 y 1832, pues en ellas se producen cambios interesantes, por decisivos, en el tratamiento de esta clase de palabra ${ }^{5}$. Estos tienen que ver con su supresión, relacionada con la forma gráfica que presenta, con la oportunidad de registrarla y con su consideración o no como arcaísmo.

1 A diferencia de esta conexión entre el participio y el adjetivo, la que se establece entre el verbo y el sustantivo hace que el infinitivo, recategorizado como sustantivo, aparezca en el diccionario no como una acepción más del sustantivo, sino como una entrada aparte (Bargalló Escrivà 1996: 41).

2 Se distingue aquí entre participio activo o de presente opuesto al pasivo, y distinto del participio pasivo con interpretación o significado activo (Felíu Arquiola 2008: 165).

3 Esta situación cambia con el paso de las ediciones - o dicho de otro modo, es exclusivo de unas edicionesy determina el tratamiento que los participios pasivos reciben en el diccionario: que el verbo esté marcado como arcaico no hace que el participio pasivo también tenga que estarlo. Asimismo, la marca diacrónica de los participios pasivos irregulares no depende de la situación del verbo correspondiente.

4 Hoy no existen en español participios de presente; sin embargo, en español antiguo eran abundantes (RAEASALE 2009: 2086). En la sexta edición, de 1822, se incorporaron cuatro (engargante, moderante, rebautizante, suplente) y se suprimieron treinta y dos; once no tenían marca de arcaísmo (actitante, emparante, hinchiente, permanesciente, pertenesciente, serviente, sobreviniente, solviente, suplante, supliente, tractante); los veintiuno restantes, sí (abondante, acontesciente, aparesciente, atapante, caresciente, comienzante, conosciente, contraente, crediente, desconosciente, encobriente, enflaquesciente, entropezante, fallesciente, judgante, meresciente, nasciente, obedesciente, reconosciente, trascendiente, vidiente). En la séptima, de 1832, se incorporaron dos (profetante, propagante) y se suprimieron diez (alimpiante, contradiciente, rebaptizante, regiente, regnante, repeliente, reteniente, senciente, subjuzgante, substituyente), todos arcaísmos excepto repeliente, senciente y substituyente. Contrastan estas cifras con las 334 y 5279 supresiones de participios pasivos que se producen en estas dos ediciones. 5 Mientras en la edición anterior a las aquí examinadas, la quinta, de 1817, se suprimieron cincuenta y seis participios pasivos, en estas dos lo hicieron 334 y 5279 respectivamente. 
Pero antes de abordar esos cambios y de tratar de explicar las razones que los producen, es oportuno hacer un breve recorrido por el tratamiento que el participio y su uso como adjetivo o sustantivo tienen en la gramática y el diccionario, así como mostrar la presencia que esta clase de palabra ha tenido en los diccionarios del español a lo largo de la historia.

\section{PARTICIPIO Y ADJETIVO EN LA GRAMÁTICA Y EL DICCIONARIO}

La gramática trata de la naturaleza del participio como verbo y adjetivo (Bosque 1991: 166; RAE-ASALE 2009: 2085, 2095), y así ha sido a lo largo de la historia (Gómez Asencio 1981: 313-322). Precisamente esto es lo que hace que el diccionario recoja el participio - aquel que lo recoge 6 - y, tras indicar que es una forma del paradigma verbal (Bargalló Escrivá 1996: 46-47; Luque Durán y Manjón Pozas 1997: 130), consigne como acepciones los usos adjetivales y sustantivos que pueda adoptar (Castillo Carballo 2003: 84, Martín García 2008: 149-150), con las diferencias ya apuntadas entre participio activo y pasivo. Esta conversión del participio en adjetivo (o sustantivo) puede evitar su supresión del diccionario - depende del diccionario y, en el académico, de la edición-, en caso de que se tome la decisión de eliminar aquello cuya formación sea regular (Werner 1982: 223; Alvar Ezquerra 1982 [1993]: 107; Bargalló Escrivá 1996: 47; Jiménez Ríos 1999: 69). Con todo, como clase de palabra que es, la historia muestra que se ha recogido en los diccionarios y que no era necesario, por tanto, que desarrollara acepciones adjetivales (o nominales) para su incorporación y mantenimiento, algo que ha experimentado cambios con el paso del tiempo en los distintos diccionarios ${ }^{7}$. Este hecho singulariza al participio, pues ninguna otra categoría gramatical se consigna en el diccionario para dar de ella una mera información morfológica, ni ninguna otra forma del paradigma verbal (Pena 1994-1995: 170-171; Bargalló Escrivá 1996: 41); precisamente por ello su presencia en los diccionarios varía, y en uno como el académico, con distintas ediciones, también, pues su inserción está determinada por criterios de técnica lexicográfica relativos al modo de confeccionar la obra.

\section{LA PRESENCIA DEL PARTICIPIO PASIVO EN LOS DICCIONARIOS}

El participio pasivo se recoge en los diccionarios del español - excepto en algunos, como los ya citados - y lo hace con diferencias entre ellos (Alvar Ezquerra 1982 [1993]: 106). En lo que parecen coincidir es en la escasez de su tratamiento, que debería ser más completo y pormenorizado (Luque Durán y Manjón Pozas 1997. 131; Martín García 2008: 150, 162).

Lo consigna Nebrija en el Vocabulario español-latino ("Abierto participio es de abrir. require abrir"8); en cambio, Covarrubias en el Tesoro reenvía la forma participial a la base morfológica, al verbo, y allí la explica como adjetivo (ABIERTO, vide Abrir ${ }^{9}$; ABOFE-

6 Martín García (2008: 156-157) cita dos diccionarios, el Diccionario Salamanca de la lengua española (Madrid, Santillana-Universidad de Salamanca, 1996) y el Diccionario de uso del español actual (Madrid, SM, 1996), que no recogen más que los usos adjetivales y sustantivos del participio.

7 Duro (1980) trata de las diferencias entre participio y adjetivo en la lexicografía y su repercusión en la lematización. Defiende que el participio se recoja como forma flexiva del verbo, o como entrada con estatus similar a otra clase de palabra, sea su función verbal o nominal.

8 Es excepcional; en este vocabulario abundan formas participiales explicadas como adjetivos.

9 "ABIERTO, credito abierto, termino de mercaderes: quando no esta limitado: resto abierto, quando el q[ue] 
TEAR y ABOFETEADO, vide Bofeton ${ }^{10}$ ). Terreros en su Diccionario vuelve a consignar el participio (ACABALLERADO, part. pas.; ESCRITO, part. pas.). En los diccionarios publicados en el siglo XIX hay, de nuevo, diferencias entre ellos: lo recogen Núñez Taboada (ABAJADO. p. p. de ABAJAR; ABALDONADO. p. p. de ABALDONAR ${ }^{11}$ ), Domínguez (ABAJADO, DA. part. pas. de Abajar) ${ }^{12}$ o Zerolo (ABALAGADO, DA. 1 p. p. de ABALAGAR $^{13}$; ABALAUSTRADO p. p. de ABALAUSTRAR) ${ }^{14}$; Salvá y Gaspar y Roig, por el contrario, solo registran el uso adjetivo de lo que en su origen es un participio (ABELLACADO, DA. adj. 'El que acostumbra obrar ruin y pícaramente', en el primero, y ABANDONADO. adj. s. 'perezoso, desaseado, desidioso, vicioso', en el segundo) ${ }^{15}$.

En el siglo XX, Julio Casares en el Diccionario ideológico de la lengua española, María Moliner en el Diccionario de uso del español y Manuel Seco, Olimpia Andrés y Gabino Ramos en el Diccionario del español actual, por citar tres obras representativas, también presentan diferencias al consignar esta clase de palabra: así, mientras Casares la recoge en unos casos (ABORRECIDO, DA. p. p. de Aborrecer; ESCRITO, TA. p. p. de Escribir) ${ }^{16}$, en otros solo ofrece usos adjetivales (ABOCHORNADO, DA. adj. Bochornoso ${ }^{17}$; Moliner la presenta bajo el verbo correspondiente e indica que es participio o participio adjetivo (ADEREZADO, A. Participio, s.v. ADEREZAR; ADHERIDO, A. Participio adjetivo, s.v. ADHERIR ${ }^{18}$ ); y en el $D E A$ se recoge el valor del participio como primera acepción (ADORMILADO, DA. adj. 1. part. $\rightarrow$ ADORMIR; ADOSADO, DA.

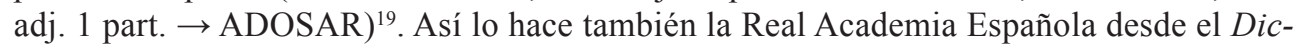
cionario de autoridades; en aquel diccionario aparece sistemáticamente tras el verbo, lo que es revelador de la consideración dependiente, como forma del paradigma verbal, que

juega tiene libertad de poder hacer el resto q[ue] quisiere."

10 "[...] Abofetear, dar bofetones. Abofeteado, el que los ha recebido."

11 De la voz escrito este diccionario recoge dos lemas: uno como participio pasivo (ESCRITO p. p. irreg. de ESCRIBIR) y otro como sustantivo.

12 En el mismo lema, dos acepciones: "ESCRITO, TA. part. pas. irr. de Escribir // s. m. Composicion ú obra de algun autor."

13 La segunda acepción es "adj. Parecido al bálago."

14 En este diccionario el uso sustantivo de escrito aparece antes que el de participio, que se consigna en una suerte de subacepción.

15 Salvá recoge también los participios pasivos irregulares (“ACCENSO, SA. p. p. irreg. y ant. de ACCENDER"). Y en aquellos, como escrito, que tienen otros usos, además del participial, indica como primera acepción que es participio pasivo irregular. Le siguen los usos como sustantivo. A diferencia de él, en el diccionario de Gaspar y Roig solo se consigna el uso sustantivo de la voz escrito.

16 La segunda acepción es: "m. Carta, documento o cualquiera papel manuscrito." También registra formas irregulares (“ABIERTO, TA. p. p. irregular de Abrir") y participios de presente ("DISONANTE. p. a. de Disonar").

17 Esta voz puede tomarse como adjetivo derivado de bochorno. También es participio pasivo del verbo abochornar. Véase para ello el DRAE s. v. abochornado.

18 Esta forma, junto con otras de la familia léxica, se registra bajo la base de la derivación, que funciona como lema (Alvar Ezquerra 1982 [1993]: 95). Martín García (2008: 153) se fija en la segunda edición de este diccionario y distingue cuatro modos de registrar los participios: 1) participio adjetivo de + verbo, tipo que puede incluir una subacepción que especifica la naturaleza adjetiva del participio; 2) participio con dos acepciones, una participial y otra adjetival (esta puede aparecer también como subacepción); 3) participio con dos acepciones también, una de participio adjetivo y otra de adjetivo; 4) el cuarto tipo recoge aquellos casos en que se indica que es participio de + verbo. Hay, también, como en los diccionarios anteriores, usos como sustantivo: "ESCRITO, TA. 1. Participio adjetivo. (nombre, en masculino). Cosa escrita, de cualquier naturaleza, extensión, etc."

19 A esta primera acepción le siguen las de adjetivo y sustantivo. 
se le otorga a esta clase de palabra (González Ollé 2014: 102) ${ }^{20}$. En ediciones posteriores empiezan a producirse cambios ${ }^{21}$.

\section{EL TRATAMIENTO DE LOS PARTICIPIOS PASIVOS EN EL DRAE}

Los participios pasivos se recogen, como se acaba de apuntar, en el diccionario de la Real Academia Española desde Autoridades 1726-1739. Para Luque Durán y Manjón Pozas (1997: 117) la atención es escasa e irregular. En las Reglas de 1743 (apud Freixas 2012: 305) se insiste en que se han de incluir los derivados "que tuvieren autoridad"22: participios activos, pasivos, aumentativos, diminutivos, superlativos y adverbios en -mente. Más tarde, en el prólogo de la segunda edición de este diccionario, de 1770, se informa del modo como se registran y del lugar en que lo hacen, que cambia con respecto a la edición anterior:

$\mathrm{Y}$ en los nombres aumentativos, diminutivos, superlativos y participios pasivos solo se expresa, quando se dice su calidad, el positivo ó verbo de que salen ó se derivan, por no ser necesario mas para entender su significacion (Autoridades 1770: prólogo).

No se pone latin á los participios pasivos, porque no le necesitan, teniendole los verbos á que se refieren: y de lo contrario se seguiria haber de poner á cada participio otros tantos latines como son las significaciones de su mismo verbo y de las frases que con él se forman, lo que serviria mas de confusion, que de facilitar su inteligencia (Autoridades 1770: prólogo).

En la colocacion de las voces se sigue rigurosamente el órden alfabético, observando en quanto á su ortografía las últimas reglas que la Academia ha establecido en el tratado que ha impreso: y así se ponen los participios activos y pasivos en el preciso lugar que les corresponde, y no á continuacion de sus verbos, como se hizo antes (Autoridades 1770: prólogo).

No se vuelve a tratar acerca de esta clase de palabra hasta la séptima edición, de 1832, en que se decide su supresión (Clavería 2016: 106; Freixas y Clavería 2018: 101) ${ }^{23}$ :

Estas supresiones comenzaron á hacerse en la sexta edicion y para mayor ahorro de artículos inútiles se suprimen tambien en esta los participios pasivos regulares, los adverbios en mente que proceden de superlativos, y además otros términos, que, pudiéndose fácilmente formar, aunque por esta razon no disuenen al oirse, no son con todo eso de uso general, ó no se hallan autorizados en los clásicos (DRAE 1832: prólogo).

Tras esa decisión, no hay ninguna mención al tratamiento de los participios pasivos hasta la vigesimosegunda edición, de 2001 (DRAE 2001: XXXVII), a pesar de que se reincorporan en la decimoquinta. En unas "Advertencias para el uso de este diccionario", que no

20 Esta localización cambia en el diccionario de 1770, como se indica más adelante.

21 Para el tratamiento del participio en otros diccionarios, véase Bargalló Escrivá (1996: 46-50) y Martín García (2008: 156-157).

22 Se recogen sin necesidad de cita.

23 No se incorpora ningún participio pasivo en 1832 ( $7^{\mathrm{a}}$ edición); la edición anterior, que, como se indica en este prólogo y se constata más adelante, ya presenta la supresión de participios, sí registró nuevas incorporaciones (en las enumeraciones o listas señaladas a continuación se citan los participios solo por la forma masculina por motivos de espacio): aterrecido, besuqueado, desembalado, exportado, garantido, infurtido, ramoneado, realizado, reanimado, recompuesto, reido, repoblado, repulido, requintado, rujiado, saboreado). No obstante, todos, excepto recompuesto, se documentan solo en esta edición de 1822 ( $6^{\text {a }}$ edición). 
tienen comparación con las que habían venido apareciendo desde la edición decimoquinta —entonces como "Reglas" y más tarde, en la decimonovena, como "Advertencias"—, se dedica un apartado a los participios. En él se advierte de su uso como adjetivo o sustantivo - con significado distinto al verbo-, lo que hace que la información relativa a la clase de palabra originaria, forma del paradigma verbal y base de la derivación, aparezca desde entonces - y esto sí es novedoso - en el paréntesis etimológico ${ }^{24}$; se informa, asimismo, de que los participios irregulares se recogen en el lugar alfabético que les corresponde (ABANDERADO, DA. (Del part. de abanderar). 1. m. y f. Persona que lleva una bandera en las procesiones u otros actos públicos; ABANDONADO, DA. (Del part. de abandonar). 1. adj. Descuidado, desidioso. // 2. Sucio, desaseado; IMPRESO (Del part. irreg. de imprimir). 1. $\mathrm{m}$. Libro, folleto u hoja impresos [...]).

\section{LA SEXTA EDICIÓN, 1822}

Aunque no se declaró hasta la séptima edición que se suprimirían los participios pasivos, ya en la edición anterior, la sexta, de 1822, se suprimieron algunos (tabla 1) y con ellos los verbos correspondientes ${ }^{25}$ :

\begin{tabular}{|c|c|c|c|}
\hline Edición & Supresiones $^{26}$ & $\begin{array}{c}\text { Supresiones de } \\
\text { participios pasivos }\end{array}$ & $\begin{array}{c}\text { Supresiones de participios } \\
\text { pasivos arcaicos }\end{array}$ \\
\hline $6^{\mathrm{a}}$ ed. 1822 & 2348 & $334(14.2 \%)$ & $193(57.7 \%)$ \\
\hline
\end{tabular}

Tabla 1. Número de participios pasivos suprimidos en la $6^{\mathrm{a}}$ edición del $D R A E$.

La novedad de esta edición es la eliminación de "artículos que [la Academia] creyó podrían excusarse sin perjuicio de la claridad conveniente y con mucho ahorro de palabras" (DRAE 1822: Prólogo), entre los cuales estaban los participios (y verbos) que presentaban diferencias gráficas correspondientes con otras formas usuales ${ }^{27}$. Con ellos es posible establecer dos grupos ${ }^{28}$. Al primero pertenecen los que tienen marca de arcaísmo: en él hay dos subgrupos, uno en el que el participio y el verbo tienen marca (tabla 2) y otro en el que el participio está marcado y el verbo no (tabla 3 ):

24 La información etimológica se contiene en el interior del paréntesis etimológico, situado tras el lema, si bien hay excepciones determinadas por el tipo de palabra y su definición, palabras cuya definición informa del origen (Seco 1987: 17 y nota 6).

25 En la quinta edición, de 1817, se suprimieron cincuenta y seis participios pasivos, seis marcados como arcaísmos (aoxado, axado, confondido, conquesto, resolvido, subjecto). Se habían introducido en Autoridades (retido, seqüestrado, transcendido, transmutado, tresquilado, ubicado, vedriado), en 1770 (actualizado, anarangeado, aoxado), en la edición de 1780 (confondido, conquesto), en el suplemento de 1780 (virado), en 1791 (desexecutado, enterpuesto, estroido, estruido, fantasticado, fengido) y en 1803 (axado, estripado, goardado, gomitado, gracejado, hespedado, preventido, previlegiado, recebido, reconoscido, rescebido, rescibido, resolvido, resuscitado, retificado, retulado, sanctiguado, seelado, servado, siguido, sincelado, sintido, sobido, sofrido, sotilizado, suadido, subjecto, subtiliado, subtilizado, surcido, tallescido, temprado, terrescido, tondido, toxicado, trespadado, xeringado).

26 Se pueden consultar los datos de adición y supresión de cada edición en la dirección web: http://draesxix. wixsite.com/draesxix. Esta cifra indica los lemas y formas de lema suprimidos.

27 No hace falta decir que los que no estaban en esta situación se mantuvieron.

28 Se marcan con asterisco los verbos que no se suprimen. 
abarrenado (abarrenar), abarrido (abarrer), abastado (abastar*), ablandescido (ablandescer), aborrescido (aborrescer), abtorizado (abtorizar), abuchornado (abuchornarse), acaescido (acaescer), acaparrado (acaparrarse), acebtado (acebtar), acecalado (acecalar), aclarescido (aclarescer), acomparado (acomparar), aconseguido (aconseguir), aconseyado (aconseyar), aconsolado (aconsolar), acontado (acontar), acontagiado (acontagiar), acontentado (acontentar), acontescido (acontescer), acontrastado (acontrastar), acotejado (acotejar), acrebillado (acrebillar), acrescido (acrescer), acuadrellado (acuadrellar) ${ }^{29}$, adaragado (adaragarse), adebdado (adebdar), adereszado (adereszar), adevinado (adevinar), adormescido (adormescer), adquerido (adquerir), adurmido (adurmirse), afalagado (afalagar), afecionado (afecionar), afortalescido (afortalescer ${ }^{30}$ ), agradescido (agradescer), agranguenado (agranguenarse), ahermoseado (ahermosear), ahoradado (ahoradar), aleviado (aleviar), aliquidado (aliquidar), almizcado (almizcar), almizcrado (almizcrar), amedicinado (amedicinar), amejorado (amejorar), amelecinado (amelecinar), amencionado (amencionar), amollescido (amollescer), amortescido (amortescer), añedido (añedir), anesciado (anesciarse), antecipado (antecipar), aotado (aotarse), apacificado (apacificar), apalpado (apalpar), aparescido (aparescer), apascentado (apascentar), apensionado (apensionar), aperroquiado (aperroquiarse), apertrechado (apertrechar), apostrado (apostrarse), apregonado (apregonar), apresciado (apresciar), apresentado (apresentar), apresionado (apresionar), aprofanado (aprofanar), aproveído (aproveer), arrecogido (arrecoger), arrevuelto (arrevolver), asasinado (asasinar), aseñalado (aseñalar), aseñoreado (aseñorear), aserenado (aserenar), asinado (asinar), asosegado (asosegar), asotilizado (asotilizar), asperado (asperar), astragado (astragar), asufrido (asufrir), asulcado (asulcar), atalado (atalar), atapado (atapar), atemido (atemer), atemplado (atemplar), atemprado (atemprar), aterrescido (aterrescer), atomecido (atomecerse*), atomescido (atomescerse*), atordido (atordirse), atrebuido (atrebuir), atrebutado (atrebutar y atrebutarse), atumescido (atumescerse), ayegado (ayegar), ayontado (ayontar)

bastescido (bastescer), bendicido (bendicir*), beneito (beneicir), broñido (broñir)

cabsado (cabsar), calientado (calientar), carcaveado (carcavear*) carpido (carpir*), cativado (cativar*), cementado (cementar), cicalado (cicalar*), circoscrito (circoscribir), cobdiciado (cobdiciar), cobierto (cobrir), cognoscido (cognoscer), cognoszudo (cognoscer), coitado (coitar), coligido (coligir), colleito (coller*), comienzado (comienzar) comongado (comongar), compenzado (compenzar), compezado (compezar), complescido (complescer), complido (complir), compremido (compremir), comprido (comprir), concibido (concibir*), concorrido (concorrer), condemnado (condemnar), confacionado (confacionar), conoscido (conoscer*), conoscudo (conoscer*), conoszudo (conoscer*), conozudo (conoscer*), conscebido (conscebir), consegrado (consegrar*), contractado (contractar*), corrigido (corrigir), corrumpido (corrumpir), cortido (cortir), crebantado (crebantar), crebrantado (crebrantar), credido (creder), crescentado (crescentar), crescido (crescer), cudiciado (cudiciar)

dapnado (dapnar), debujado (debujar), decernido (decerner), deminuido (deminuir), deraigado (deraigar), descobierto (descobrir), descobrido (descobrir), descomongado (descomongar), desculpado (desculpar), desenfamado (desenfamar), desfamado (desfamar*), desfrazado (desfrazar), desgustado (desgustar), deslocado (deslocar), desmamparado (desmamparar), desparescido (desparescerse), destayado (destayar), destemprado (destemprar), destribuido (destribuir), destroido (destroir), devidido (devidir)

empuesto (emponer), escoieto (escoier)

impropriado (impropriar)

Tabla 2. Grupo 1.1: Participio pasivo y verbo con marca de arcaísmo.

29 Con cambio gráfico $<\mathrm{q}>$ por $<\mathrm{c}>$.

30 Este verbo se había suprimido en 1817. 
No hay participios pasivos arcaicos eliminados en esta edición en letras posteriores a la D, hecho significativo, como se expondrá más adelante (los participios citados de las letras E e I, como puede verse por su número, son excepcionales). Los casos en los que el participio pasivo está marcado y el verbo no (tabla 3) también son una excepción, pues se trata de participios irregulares o cuya morfología es antigua ${ }^{31}$ :

\begin{tabular}{|l|}
\hline abatudo (abatir* no ant.), aflito (afligir* no ant.) \\
\hline cernudo (cerner* no ant.) \\
\hline defendudo (defender* no ant.), desconoscido (desconoscer ${ }^{32}$ ), disolvido (disolver* no ant.) \\
\hline eleito (elegir* no ant.), escribido (escribir* no ant.) \\
\hline instruto (instruir* no ant.) \\
\hline
\end{tabular}

Tabla 3. Grupo 1.2: Participio pasivo con marca de arcaísmo y verbo sin marca.

En este subgrupo, los verbos con los que se relacionan los participios no son eliminados, y no lo son porque no presentan una grafía que determine su supresión, ni que los haga arcaicos.

Al segundo grupo pertenecen los participios pasivos sin marca de arcaísmo. En él pueden establecerse, de nuevo, dos subgrupos: uno, en el que el participio y el verbo no tienen marca de arcaísmo (tabla 4), y otro en el que el participio no es arcaico y el verbo sí (tabla 5):

\begin{tabular}{l}
$\begin{array}{l}\text { acachado (acacharse), acapizado (acapizarse), acombado (acombar), actitado (actitar), agujerado } \\
\text { (agujerar*), almonedado (almonedear*), amantillado (amantillar), amimado (amimar), apeñuscado } \\
\text { (apeñuscar), atorzonado (atorzonarse) }\end{array}$ \\
\hline $\begin{array}{l}\text { desacabalado (desacabalar), desinseculado (desinsecular), desminuido (desminuir), desparvado } \\
\text { (desparvar) }\end{array}$ \\
\hline emburriado (emburriar), enruinescido (enruinescer), escrudiñado (escrudiñar) \\
\hline fumentado (fumentar) \\
\hline guarnescido (guarnescer) \\
\hline $\begin{array}{l}\text { injerto (injerir*), injerido (injerir*, injerirse*33), injertado (injertar), inseculado (insecular), inviado } \\
\text { (inviar) }\end{array}$ \\
\hline paragonado (paragonar*) \\
\hline revidado (revidar) \\
\hline $\begin{array}{l}\text { sobreescrito (sobreescribir), subscripto (subscribir*), subscrito (subscribir*), solevado (solevar), } \\
\text { sostituido (sostituir*), supositado (supositar), surto (surgir*) }\end{array}$ \\
\hline
\end{tabular}

Tabla 4. Grupo 2.1: Participio pasivo y verbo sin marca de arcaísmo.

31 Véase lo dicho más arriba acerca de la marcación diacrónica de los participios pasivos irregulares.

32 No tiene marca de arcaísmos, quizá por error.

33 En injerir e injerirse con cambio gráfico $<\mathrm{j}>$ por $<\mathrm{g}>$. 
Lo que llama la atención de este subgrupo es la falta de marca diacrónica tanto en el participio como en el verbo, si se compara con el grupo anterior, y en el verbo, si la comparación se establece con el subgrupo señalado a continuación. Los verbos no tienen esa marca de arcaísmo porque algunos no son variantes gráficas (acapizar, almonedear, amantillar, desparvar, injerir, injerirse, injertar, solevar, supositar, surgir) y, por tanto, no son arcaísmos gráficos; otros no la tienen porque, aun siendo variantes gráficas, tienen otra marcación adicional (acacharse, actitar, amimar, emburriar, revidar ${ }^{34}$ ). Por último, los hay en los que no es fácil explicar la falta de marca diacrónica (acombar, agujerar, apeñuscar, atorzonarse, desacabalar, desinsecular, desminuir, fumentar, guarnescer, insacular, inviar, sobreescribir, subscribir, sostituir), pues no se distinguen de los señalados a continuación.

Más abundantes son los casos de este otro subgrupo en el que el participio no es arcaico y el verbo sí (tabla 5) (los ejemplos pertenecen a letras posteriores a la D), lo que parece responder a un cambio en su tratamiento lexicográfico:

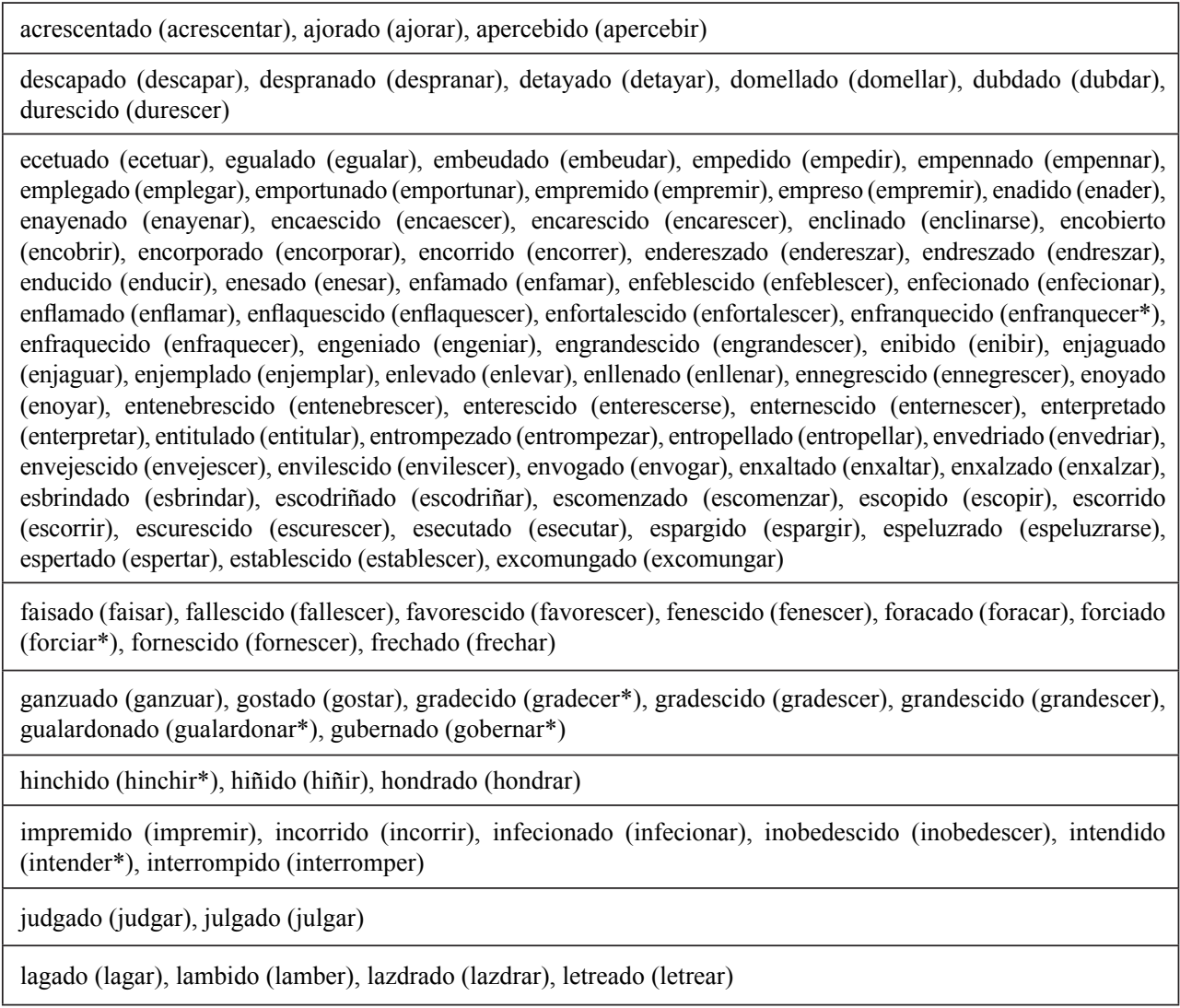

34 De acacharse se lee en Autoridades 1726-1739: "v. r. Lo mismo que agacharse. Es voz vulgar y rústica, que se usa en el Reino de Murcia. Vease Agacharse" y en 1803: "p. Murc. y otr. par." En 1817: actitar. "v. a. for. p. Ar. Hacer actos judiciales ó actuar"; amimar "v. a. Lo mismo que MIMAR. Úsase en algunas provincias"; emburriar “v. a. p. Ast. Lo mismo que EMPUJAR"; revidar "v. a. En algunas partes envidar al que habia envidado." 


\begin{tabular}{|l|}
\hline llevantado (llevantar) \\
\hline $\begin{array}{l}\text { madurgado (madurgar), maltractado (maltractar), mamparado (mamparar), melecinado (melecinar*), menuszado } \\
\text { (menuszar), mercadanteado (mercadantear), merescido (merescer) }\end{array}$ \\
\hline nascido (nascer) \\
\hline obedescido (obedescer), ordinado (ordinar*) \\
\hline $\begin{array}{l}\text { pendrado (pendrar), perescido (perescer), perficionado (perficionar), podrescido (podrescer), preindado } \\
\text { (preindar), prejudicado (prejudicar), prenosticado (prenosticar), puyado (puyar) }\end{array}$ \\
\hline $\begin{array}{l}\text { reblandescido (reblandescer), recrescido (recrescer), redemido (redemir), refenchido (refenchir), referendado } \\
\text { (referendar), refollado (refollar), regradescido (regradescer), rehirmado (rehirmar), rejuvenescido (rejuvenescer), } \\
\text { requirido (requirir), rescrecido (rescrecer), restreñido (restreñir), reverdescido (reverdescer), ruciado (ruciar) }\end{array}$ \\
\hline $\begin{array}{l}\text { safumado (safumar), señorizado (señorizar), sillado (sillar), sinado (sinar), siñado (siñar), siringado (siringar), } \\
\text { somido (somir), sorrabado (sorrabar) }\end{array}$ \\
\hline tesaurizado (tesaurizar), tesorado (tesorar), tesorizado (tesorizar) \\
\hline
\end{tabular}

Tabla 5. Grupo 2.2: Participo pasivo sin marca de arcaísmo y verbo con marca de arcaísmo.

La diferencia entre este subgrupo 2.2 (tabla 5) y el anterior 1.1 (tabla 2) está en marcar o no como arcaísmo el participio, lo que parece responder a la aplicación de un criterio de técnica lexicográfica, de confección del diccionario, más que a las propias condiciones de uso del participio, pues tanto el verbo como el participio presentan una grafía desusada, si es esto lo que determina la marcación: en el grupo anterior, la relación del verbo y el participio dentro del paradigma verbal determina que se marquen los dos, si uno, el verbo, está marcado; en cambio, en este grupo el criterio aplicado ya es otro, y el hecho de que el verbo sea anticuado no justifica, o no determina, que el participio también tenga que serlo, a pesar de presentar la misma variación gráfica.

Si se comparan las letras a las que pertenecen los participios pasivos eliminados, se observa, como se ha apuntado más arriba, que a partir de la letra E los participios pasivos no están marcados como arcaísmos y el verbo sí, lo que confirma esta idea de que su marcación responde al modo de tratar esta clase de palabra en el diccionario y no a sus condiciones de uso, ni al hecho de que presente una determinada grafía. Son razones lexicográficas, fruto de los criterios empleados en la confección del repertorio léxico, las que determinan la ausencia de la marca y no razones filológicas, por su presencia en textos de un determinado tipo o de una determinada época. De no ser esto así, es decir, de no ser esta la razón, es muy difícil explicar por qué a partir de una letra concreta del diccionario las voces tienen un tratamiento diferente. Esa diferencia entre letras resulta de la edición en que se introdujeron estos participios pasivos ahora eliminados y de las observaciones relativas a la revisión de la edición, que se apuntan en los prólogos correspondientes. En la tabla 6 se recogen los participios ordenados por la edición en que tienen su primera documentación y se indica si tenían o no marca diacrónica ${ }^{35}$ :

35 Se ponen en cursiva los participios pasivos que tienen marca de arcaísmo y en redonda los que no la tienen en la edición de 1817, la última que los registró. Se indican con "n.m” las voces que no tenían marca de arcaísmo en la primera edición que las documentó. 


\begin{tabular}{|c|c|}
\hline Edición & Incorporación de participios pasivos eliminados en 1822 \\
\hline \multirow[t]{8}{*}{$\begin{array}{c}\text { Autoridades } \\
1726-1739\end{array}$} & $\begin{array}{l}\text { abastado (n.m), acontado (n.m), acontagiado (n.m.), apalpado }{ }^{36} \text {, apregonado, } \\
\text { apresentado, atalado (n.m), atapado (n.m), atemprado } \\
\text { acachado (n.m), actitado (n.m), agujerado (n.m), ajorado (n.m), apeñuscado } \\
\text { (n.m), apercebido (n.m), atorzonado (n.m) }\end{array}$ \\
\hline & carcaveado (n.m), carpido (n.m), coitado, complido ${ }^{38}$ \\
\hline & deraigado \\
\hline & forciado \\
\hline & inxerido (n.m), inxerto (n.m) \\
\hline & perficionado (n.m) \\
\hline & ruciado $(\mathrm{n} . \mathrm{m})^{9}$ \\
\hline & solevado (n.m), surto (n.m) \\
\hline Autoridades 1770 & $\begin{array}{l}\text { abuchornado (n.m), acaparrado, (n.m), acomparado, aconseguido, } \\
\text { aconsolado, acontentado, acontrastado, acotejado, ahermoseado, aleviado, } \\
\text { aliquidado, amejorado, amelecinado, amollescido, aperroquiado, apostrado, } \\
\text { apresciado, apresionado, aprofanado, aproveido, arrecogido, asasinado, } \\
\text { aseñoreado, asinado, asosegado, asotilizado, astragado, asulcado (n.m), } \\
\text { atemplado, aterrescido, atrebutado, ayegado } \\
\text { acapizado (n.m), amantillado (n.m), amimado (n.m) }\end{array}$ \\
\hline \multirow[t]{2}{*}{$1^{\mathrm{a}}$ ed. 1780} & aserenado \\
\hline & $\begin{array}{l}\text { cabsado, cativado, cicalado, cobdiciado, cobierto, cognoscido, comienzado, } \\
\text { comongado, compezado, complescido, compremido, comprido, concibido, } \\
\text { condemnado, confacionado, conoscido, conoscudo, conoszudo, conozudo, } \\
\text { conscebido, consegrado (n.m), corrumpido, cortido, crebantado }\end{array}$ \\
\hline \multirow[t]{2}{*}{$1^{\mathrm{a}}$ ed. 1780 Supl. } & $\begin{array}{l}\text { abarrenado, aborrescido, abtorizado, acaescido, acebtado, acecalado, } \\
\text { acrescido, adaragado, adebdado, adormescido, afecionado, aflito, } \\
\text { agradescido, agranguenado (n.m), almizcado, almizcrado, amencionado, } \\
\text { amortescido, añedido, apacificado, aparescido, apascentado, aquadrellado, } \\
\text { arrevuelto, aseñalado, atomescido, atordido (n.m) }\end{array}$ \\
\hline & bendicido, beneito, broñido \\
\hline \multirow[t]{2}{*}{$2^{\mathrm{a}}$ ed. $1783 \mathrm{Supl}$} & acontescido, atumescido, ayontado \\
\hline & circoscrito, crebrantado \\
\hline $3^{\mathrm{a}}$ ed. 1791 & cementado, corrigido \\
\hline
\end{tabular}

36 "Es voz de poco uso."

37 En 1770 se marcan como arcaísmo abastado, apalpado y atapado; en 1780 lo hace atalado; y en 1803 acontado y acontagiado.

38 Carcaveado y carpido se marcan como anticuados en 1780.

39 En 1780 se marca como anticuado. 


\begin{tabular}{|c|c|}
\hline Edición & Incorporación de participios pasivos eliminados en 1822 \\
\hline \multirow[t]{3}{*}{$3^{\mathrm{a}}$ ed. 1791} & $\begin{array}{l}\text { debuxado }{ }^{40} \text {, decernido, defendudo, deminuido, descobierto (n.m), } \\
\text { descomongado, desconoscido, desculpado, desenfamado, desmamparado, } \\
\text { desparescido, destayado, destemprado, destribuido, destroido, disolvido } \\
\text { descapado }^{41} \text { (n.m), dubdado (n.m), durescido (n.m) }\end{array}$ \\
\hline & $\begin{array}{l}\text { eleyto, empuesto, escribido, enadido } \\
\text { egualado, empedido, empennado, emplegado (n.m), emportunado (n.m), } \\
\text { empremido, empreso, encaescido (n.m), encobierto }{ }^{42} \text {, encorporado (n.m), } \\
\text { encorrido (n.m), endereszado (n.m), enesado (n.m), enfamado (n.m), } \\
\text { enfeblescido (n.m), enfecionado, enflamado, enflaquescido, enfortalescido, } \\
\text { enfranquecido, enfraquecido, engeniado, enibido, enjaguado, enjemplado } \\
\text { (n.m), enlevado, enllenado (n.m), enoyado, enruinescido(n.m.), entenebrescido, } \\
\text { entitulado, entropellado, envedriado, envilescido, envogado (n.m), enxaltado, } \\
\text { enxalzado, esbrindado (n.m), escodriñado, escomenzado, escopido, escorrido } \\
\text { (n.m), escurescido, esecutado, espargido, espeluzrado (n.m), espertado, } \\
\text { excomungado }\end{array}$ \\
\hline & fallescido, favorescido, fenescido, foracado, fornescido, frechado \\
\hline \multirow[t]{8}{*}{$4^{\mathrm{a}}$ ed. 1803} & $\begin{array}{l}\text { abarrido, abatudo, ablandescido, aclarescido, aconseyado, acrebillado, } \\
\text { adereszado, adevinado, adquerido, adurmido, afalagado, afortalescido, } \\
\text { ahoradado, amedicinado, anesciado, antecipado, apensionado, apertrechado, } \\
\text { asufrido, atemido, atomecido, atrebuido } \\
\text { acombado (n.m) }\end{array}$ \\
\hline & bastescido \\
\hline & calientado, cernudo, coligido, compenzado, contractado, cudiciado \\
\hline & $\begin{array}{l}\text { dapnado, descobrido, desfamado, desfrazado, desgustado, deslocado, } \\
\text { desminuido }^{43} \text { (n.m), devidido } \\
\text { desacabalado (n.m), desinseculado (n.m), desparvado (n.m), despranado, (n.m) } \\
\text { detayado (n.m), domellado (n.m) }\end{array}$ \\
\hline & $\begin{array}{l}\text { escoieto } \\
\text { ecetuado (n.m), embeudado (n.m), emburriado (n.m), enayenado (n.m), } \\
\text { encarescido (n.m), enclinado (n.m), endreszado (n.m), enducido (n.m), } \\
\text { engrandescido (n.m), ennegrescido (n.m) }{ }^{44} \text {, enterescido (n.m), enternescido } \\
\text { (n.m), enterpretado (n.m), entrompezado (n.m), envejescido (n.m), escrudiñado } \\
\text { (n.m), establescido (n.m) }\end{array}$ \\
\hline & faisado (n.m), fumentado (n.m) \\
\hline & $\begin{array}{l}\text { ganzuado (n.m), gostado (n.m), gradecido (n.m), gradescido (n.m), grandescido } \\
\text { (n.m), gualardonado (n.m), guarnescido (n.m), gubernado (n.m) }\end{array}$ \\
\hline & hinchido (n.m), hiñido (n.m), hondrado (n.m) \\
\hline
\end{tabular}

40 En esta edición es adjetivo, no participio.

41 Se marcó como voz de raro uso.

42 Se elimina la marca de anticuado en 1803.

43 No tiene marca; el verbo correspondiente no tiene tampoco marca de arcaísmo.

44 Figura como ennesgrecido, por errata. 


\begin{tabular}{|c|c|}
\hline Edición & Incorporación de participios pasivos eliminados en 1822 \\
\hline \multirow[t]{10}{*}{$4^{\mathrm{a}}$ ed. 1803} & $\begin{array}{l}\text { impropriado (n.m), instruto } \\
\text { impremido (n.m), incorrido (n.m), infecionado (n.m), inxertado (n.m), } \\
\text { inobedescido (n.m), inseculado (n.m), intendido (n.m), interrompido (n.m), } \\
\text { inviado (n.m) }\end{array}$ \\
\hline & judgado (n.m), julgado (n.m) \\
\hline & lagado (n.m), lambido (n.m), lazdrado ${ }^{15}$ (n.m), letreado (n.m), llevantado (n.m) \\
\hline & $\begin{array}{l}\text { madurgado (n.m), maltractado (n.m), mamparado (n.m), melecinado (n.m), } \\
\text { menuszado (n.m), mercadanteado (n.m), merescido (n.m) }\end{array}$ \\
\hline & nascido (n.m) \\
\hline & obedescido (n.m), ordinado (n.m) \\
\hline & $\begin{array}{l}\text { paragonado (n.m), perescido (n.m), podrescido (n.m), prejudicado (n.m), } \\
\text { prenosticado (n.m), preyndado (n.m), puyado (n.m) }\end{array}$ \\
\hline & $\begin{array}{l}\text { reblandescido (n.m), recrescido (n.m), redemido (n.m), refenchido (n.m), } \\
\text { referendado (n.m), refollado (n.m), regradescido (n.m), rehirmado (n.m), } \\
\text { rejuvenescido (n.m), requirido (n.m), rescrecido (n.m), restreñido (n.m), } \\
\text { reverdescido (n.m), revidado (n.m) }\end{array}$ \\
\hline & $\begin{array}{l}\text { safumado (n.m), señorizado (n.m), sillado (n.m), sinado (n.m), siñado } \\
\text { (n.m), siringado (n.m), sobreescrito }{ }^{46} \text { (n.m), somido (n.m), sorrabado (n.m), } \\
\text { subscripto }^{47} \text { (n.m), subscrito }{ }^{18} \text { (n.m), sostituido (n.m), supositado (n.m) }\end{array}$ \\
\hline & tesaurizado (n.m), tesorado (n.m), tesorizado (n.m) \\
\hline \multirow[t]{2}{*}{$4^{\mathrm{a}}$ ed. 1803 Supl } & acrescentado (n.m), asperado (n.m) \\
\hline & credido, crescentado, crescido \\
\hline \multirow[t]{3}{*}{$5^{\mathrm{a}}$ ed. 1817} & aotado, almonedado (n.m) \\
\hline & cognoszudo, colleito, concorrido \\
\hline & pendrado (n.m) \\
\hline
\end{tabular}

Tabla 6. Incorporación de participios pasivos eliminados en 1822.

Tras el Diccionario de autoridades, las ediciones que se publicaron después introdujeron participios pasivos; de hecho, de los señalados aquí, muy pocos estaban ya en ese diccionario. En su segunda edición, de 1770, se incorporaron en la letra A muchos, la mayoría marcados como arcaísmos; en la primera edición del DRAE, de 1780, hay un aumento de participios marcados en la letra $\mathrm{C}$, que permanecía inédita después de que se abandonara la confección de esa segunda edición de Autoridades $^{49}$; también los hay en la letra A, en el suplemento. La tercera y cuarta ediciones, de 1791 y 1803 , destacan por las letras a las que

45 Está en Autoridades 1726-1739 y en las ediciones posteriores como adjetivo anticuado. En esta edición, la cuarta, de 1803, deja de tener marca y se consigna como participio.

46 En esta edición se introduce como primera acepción la indicación de participio pasivo.

47 En la tercera edición, de 1791, aparece por primera vez y se recoge como adjetivo.

48 Está en el diccionario desde Autoridades 1726-1739 como adjetivo - excepto en la tercera edición, de 1791y se registra como participio en esta cuarta edición, de 1803.

49 Véase Seco (1991: III-IV) para conocer los avatares que determinaron el paso del Diccionario de autoridades a las ediciones del diccionario. 
pertenecen estas incorporaciones y por el hecho de que dejaran de marcarse los participios como arcaísmos: en la tercera, como se advierte en la portada, "se han intercalado en las letras D, E, F nuevos artículos"; por eso, pertenecen a estas letras los participios adicionados. Y en la cuarta la revisión llega hasta la L —revisión de esa segunda edición de Autoridades que nunca llegó a aparecer-, lo que explica la incorporación de participios pasivos en letras posteriores a la F. A partir de entonces, como refleja la edición de 1817, la situación cambia, pues apenas hay incorporaciones. Son, precisamente, estos hechos los que hacen que sean razones de técnica lexicográfica, relativas a los criterios seguidos en la confección del diccionario, las que expliquen el tratamiento dado a los participios pasivos: su inserción, su marcación y, si es el caso, su eliminación.

La supresión de arcaísmos gráficos, que, como también se ha apuntado, caracteriza a esta sexta edición ( $D R A E$ 1822: prólogo), muestra, en lo sucedido con los participios, que se empezó a aplicar lo que en la siguiente sería un acuerdo de la corporación, recogido en el prólogo: la supresión de participios pasivos regulares. A la vista de los ejemplos, puede concluirse que los participios pasivos en esta edición no se eliminaron por su condición de participios (pues se habrían eliminado todos y no fue asís ${ }^{50}$ ); tampoco porque fueran arcaísmos (pues se habrían mantenido los que no tenían esta condición): se suprimieron porque empezó a practicarse lo que sería norma en la siguiente, por presentar una grafía ya en desuso o por ser una variante gráfica de una forma usual - sin que esto les otorgara la condición de arcaísmos-, razones que explican que se eliminaran también los verbos de los que procedían.

\section{LA SÉPTIMA EDICIÓN, 1832}

Tras la práctica iniciada en la edición de 1822, en la siguiente, la séptima, de 1832 , fueron suprimidos los participios pasivos por ser participios, no por ser arcaísmos, algunos con variación gráfica y morfológica (tabla 7$)^{51}$ :

\begin{tabular}{|c|c|c|c|}
\hline Edición & Supresiones & $\begin{array}{c}\text { Supresiones de } \\
\text { participios pasivos }\end{array}$ & $\begin{array}{c}\text { Supresiones de participios } \\
\text { pasivos arcaicos }\end{array}$ \\
\hline $7^{\text {a }}$ ed. 1832 & 6399 & $5279(82.3 \%)$ & $536(10.1 \%)$ \\
\hline
\end{tabular}

Tabla 7. Supresión de participios pasivos en la $7^{\mathrm{a}}$ edición del $D R A E$.

Como en la edición anterior, los participios pasivos marcados como arcaísmos se concentran en las letras A-D, y a partir de la E no están marcados. La tabla 8 recoge el número de participios pasivos arcaicos y no arcaicos eliminados en esta edición ${ }^{52}$, ordenados por letras. Muestra cómo a partir de la letra E los participios con marca de arcaísmo son muy escasos; de hecho, de los 536, 510 se concentran en las cuatro primeras letras:

50 Se suprimieron en la edición siguiente.

51 Véase el prólogo de esta edición y lo señalado sobre ella más arriba.

52 Pueden consultarse los datos de adición y supresión en las bases de datos de cada edición en la dirección web: http://draesxix.wixsite.com/draesxix. En esas bases de datos se ofrece información muy variada: forma y cronología del lema, marcas, presencia o no en los suplementos, y observaciones diversas, tales como si el lema es múltiple, locuciones, si hay información de uso, además de la que aporta la marca, entre otras. 


\begin{tabular}{|c|c|c|c|c|c|c|c|c|c|c|c|c|c|c|c|}
\hline $\mathrm{A}$ & $297 / 695$ & $\mathrm{D}$ & $108 / 826$ & $\mathrm{G}$ & $0 / 55$ & $\mathrm{~J}$ & $1 / 34$ & $\mathrm{~N}$ & $1 / 15$ & $\mathrm{Q}$ & $0 / 7$ & $\mathrm{~T}$ & $1 / 169$ & $\mathrm{X}$ & $0 / 1$ \\
\hline $\mathrm{B}$ & $30 / 89$ & $\mathrm{E}$ & $1 / 1012$ & $\mathrm{H}$ & $1 / 59$ & $\mathrm{~L}$ & $1 / 77$ & $\mathrm{O}$ & $1 / 49$ & $\mathrm{R}$ & $1 / 377$ & $\mathrm{U}$ & $0 / 14$ & $\mathrm{Y}$ & $0 / 4$ \\
\hline $\mathrm{C}$ & $75 / 317$ & $\mathrm{~F}$ & $2 / 104$ & $\mathrm{I}$ & $2 / 146$ & $\mathrm{M}$ & $6 / 171$ & $\mathrm{P}$ & $5 / 202$ & $\mathrm{~S}$ & $0 / 207$ & $\mathrm{~V}$ & $0 / 64$ & $\mathrm{Z}$ & $0 / 32$ \\
\hline
\end{tabular}

Tabla 8. Número de participios pasivos arcaicos/no arcaicos eliminados en $1832^{53}$.

La decisión de eliminar en esta edición los participios pasivos hizo que se suprimieran solo estos y se mantuvieran los verbos correspondientes, a pesar de que algunos presentaban grafías arcaicas, lo que lleva a preguntarse por qué no habían sido suprimidas estas formas en la edición anterior:

ABSCONDIDO, DA. p. p. ant. de ABSCONDER (suprimido)

ABSCONDER. a. ant. ESCONDER. Usábase tambien como recíproco (mantenido)

ACOBDICIADO, DA. p. p. ant. de ACOBDICIAR (suprimido)

ACOBDICIAR a. ant. ACODICIAR (mantenido)

CABDELLADO, DA. p. p. ant. de CABDELLAR (suprimido)

CABDELLAR a. ant. ACAUDILLAR (mantenido)

CALLENTADO, DA. p. p. ant. de CALLENTAR (suprimido)

CALLENTAR. a. ant. CALENTAR. Usábase tambien como recíproco (mantenido)

Aquellos participios que no estaban en esta situación, es decir, que no tenían grafía arcaica, pero eran arcaísmos, fueron suprimidos también por su condición de participios, no por ser arcaísmos, pues, si la razón hubiera sido esta, se habrían eliminado también los verbos correspondientes:

ABANDALIZADO, DA. p. p. ant. de ABANDALIZAR (suprimido)

ABANDALIZAR. v. a. ant. ABANDERIZAR (mantenido)

BARATADO, DA. p. p. ant. de BARATAR (suprimido)

BARATAR. v. a. ant. Permutar ó trocar unas cosas por otras (mantenido)

CALENDADO, DA. p. p. ant. de CALENDAR (suprimido)

CALENDAR. v. a. ant. Poner en las escrituras, cartas ú otros instrumentos la fecha o data del dia, mes y año (mantenido)

Que esto efectivamente fue así, es decir, que el foco se puso en los participios pasivos y no en los arcaísmos, lo prueban ejemplos como los siguientes, en los que se elimina el participio, que no es arcaísmo, y se mantiene el verbo, que sí lo es:

EFEMINADO, DA. p. p. de EFEMINAR (suprimido)

EFEMINAR. v. a. ant. AFEMINAR (mantenido)

EMPECIDO, DA. p. p. de EMPECER (suprimido)

EMPECER. v. a. ant. Dañar, ofender, causar perjuicio (mantenido)

EMPRIMIDO, DA. p. p. de EMPRIMIR (suprimido)

EMPRIMIR. v. a. ant. IMPRIMIR (mantenido)

53 La primera cifra indica el número de participios pasivos arcaicos; la segunda, el de participios pasivos sin marca diacrónica. 
No son arcaísmos y ya sabemos por qué: porque no se marcaron como tales a partir de la letra E. No obstante, la casuística puede ser muy variada y, de hecho, lo es. Los siguientes ejemplos muestran que se suprimió el participio pasivo y el verbo, los dos arcaísmos, como se ha visto que sucedió abundantemente en la sexta edición:

ACOMANDADO, DA. p. p. ant. de ACOMANDAR (suprimido)

ACOMANDAR v. a. ant. ENCOMENDAR (suprimido)

CABZADO, DA. p. p. ant. de CABZAR (suprimido)

CABZAR. v. a. ant. de CAZAR (suprimido)

Y hasta es posible encontrar algún participio pasivo que no es arcaísmo — no tiene marca de arcaísmo - en esta séptima edición, pero lo había sido en otras anteriores:

EMPESTIFERADO, DA. p. p. de EMPESTIFERAR (suprimido)

En DRAE 1791: ant.; en DRAE 1803: sin marca.

EMPESTIFERAR. v. a. ant. APESTAR (mantenido)

Es un participio pasivo de la letra E (empestiferado), aquella a partir de la cual los miembros de esta clase de palabra dejaron de marcarse por motivos de técnica lexicográfica.

Puede concluirse, entonces, que los participios pasivos se eliminaron, primero, en la sexta edición, por tener una grafía determinada, y, después, en la séptima, por su condición de participios, no porque fueran arcaísmos. Desde entonces, el diccionario solo recoge aquellos convertidos en adjetivos (o sustantivos).

\section{LA RECUPERACIÓN DEL PARTICIPIO PASIVO}

Desde la séptima edición, de 1832, el diccionario registra - o mantiene - los participios pasivos convertidos en adjetivos y sustantivos, una consecuencia de la supresión, de la que no se dice nada en el prólogo ${ }^{54}$. Casi cien años después, en la decimoquinta, de 1925, se recuperó esta clase de palabra ${ }^{55}$, y volvió a aparecer como en las ediciones anteriores, novedad de la que tampoco se advierte ni en el prólogo, ni en las "Reglas para el uso de este diccionario." En la vigesimoprimera edición, de 2001, se elimina de nuevo, y se mantienen solo los usos adjetivales o nominales del participio, pero se advierte de este origen en el lugar destinado para tal fin: el paréntesis etimológico (Herrero Ruiz de Loizaga 2006: $157)^{56}$. La siguiente tabla recoge el tratamiento dado al participio pasivo y su relación con el adjetivo y sustantivo en las distintas ediciones del diccionario académico:

54 No hay adición de participios pasivos en las ediciones posteriores a las aquí examinadas; sí se suprimieron algunos restos de participios (ascripto, ascrito en 1837 y avenido en 1843).

55 Alvar Ezquerra (1982 [1993]: 105) señala que "hoy nadie negaría el estatuto de adjetivo a atrevido, exagerado, ni a corriente, durmiente o vituperante, por más que su origen se halle en el interior de los paradigmas verbales. $\mathrm{Y}$ sin embargo todos ellos figuran en el diccionario de la Academia calificados como participio, al menos en su primera acepción."

56 Lo hace el diccionario académico; otros repertorios léxicos, con la pretensión de ser más modernos, no hacen mención de su valor verbal inicial (Bargalló Escrivá 1996: 47). 


\begin{tabular}{|c|l|}
\hline \multicolumn{1}{|c|}{ Edición } & \multicolumn{1}{|c|}{ Voz y definición } \\
\hline Autoridades $1726-1739$ & ABARQUILLADO, DA. part. pas. Puesto en figúra de barquillo ${ }^{57}$ \\
\hline Autoridades 1770 & ABARQUILLADO, DA. part. pas. del verbo abarquillar \\
\hline $1780-1803\left(1^{\mathrm{a}}-4^{\mathrm{a}}\right)$ & ABARQUILLADO, DA. p. p. de ABARQUILLAR \\
\hline $1817-1822\left(5^{\mathrm{a}}-6^{\mathrm{a}}\right)$ & $\begin{array}{l}\text { ABARQUILLADO, DA. p. p. de ABARQUILLAR } \\
\text { ABARQUILLADO. a. adj. Lo que tiene figura de barquillo }\end{array}$ \\
\hline $1832-1869\left(7^{\mathrm{a}}-11^{\mathrm{a}}\right)$ & ABARQUILLADO. DA adj. Lo que tiene figura de barquillo \\
\hline $1884-1914\left(12^{\mathrm{a}}-14^{\mathrm{a}}\right)$ & Abarquillado, da. adj. De figura de barquillo \\
\hline $1925\left(15^{\mathrm{a}}\right)$ & $\begin{array}{l}\text { ABARQUILLADO, DA. p. p. de Abarquillar. // 2. adj. De figura de } \\
\text { barquillo }\end{array}$ \\
\hline $1936-1992\left(16^{\mathrm{a}}-21^{\mathrm{a}}\right)$ & Abarquillado, DA. p. p. de Abarquillar. // 2. adj. De figura de barquillo \\
\hline $2001-2014\left(22^{\mathrm{a}}-23^{\mathrm{a}}\right)$ & $\begin{array}{l}\text { Abarquillado, da (Del part. de abarquillar) 1. adj. De forma de } \\
\text { barquillo }\end{array}$ \\
\hline
\end{tabular}

Tabla 9. Evolución del tratamiento del participio pasivo en el diccionario académico.

\section{CONCLUSIÓN}

Lo expuesto en estas páginas muestra el tratamiento recibido por los participios pasivos en el diccionario de la Real Academia Española. Se observa que se incorporan, se suprimen y se vuelven a incorporar en distintos momentos, en distintas ediciones. Estas testimonian cambios en el quehacer lexicográfico con la adición de participios en letras concretas, aquellas que son objeto de revisión, con su marcación o no como arcaísmos, y con la conversión en adjetivos (o sustantivos), lo que determina su reincorporación para poder explicar precisamente esta conversión.

Se comprueba, asimismo, la oportunidad metodológica de examinar en el diccionario un grupo de voces con características determinadas, como este de los participios pasivos, con el fin de ver cuál ha sido su tratamiento, los cambios que han experimentado, y si su consideración como arcaísmo depende o no de que el verbo correspondiente también lo sea. Y, sobre todo, el examen de este grupo léxico ha puesto de manifiesto la importancia de las ediciones en que se registran estas voces y de los criterios lexicográficos que las guían. Ciertamente, puede concluirse que una parte de los arcaísmos léxicos del diccionario, los participios pasivos, lo han sido - y hay que decir que lo han sido porque dejan de estar marcados como arcaicos - por razones que no tienen nada que ver con la filología, esto es, con su presencia en textos de un determinado período histórico, sino con la lexicografía, con su relación con los verbos correspondientes, con su presencia en ediciones concretas y con los principios metodológicos que las determinan.

\section{REFERENCIAS BIBLIOGRÁFICAS}

Alvar Ezquerra, M. (1982 [1993]). "Diccionario y gramática", LEA, 4/2, pp. 151-212. Reimpreso en Lexicografia descriptiva. Barcelona: Vox-Biblograf, 1993, pp. 87-143.

57 No se menciona el verbo correspondiente porque el participio aparece ordenado alfabéticamente después de él. 
Bargalló Escrivá, M. (1996). “Gramática y diccionario: la flexión verbal.” En Forgas, E. (coord.). Léxico y diccionarios. Tarragona: Departament de Filologies Romàniques, Universitat Rovira y Virgili, pp. 37-54.

Bosque, I. (1991). Las categorías gramaticales. Madrid: Síntesis.

Casares, J. (1942 [1990]). Diccionario ideológico de la lengua española. Barcelona: Gustavo Gili, $17^{\mathrm{a}}$ ed.

Castillo Carballo, M. A. (2003). "La macroestructura del diccionario." En Medina Guerra, A. M. (coord.). Lexicografía española. Barcelona: Ariel, pp. 79-101.

Clavería, G. (2016): De vacunar a dictaminar: la lexicografía académica decimonónica y el neologismo. Madrid/Frankfurt: Iberoamericana/Vervuert.

Duro, A. (1980). "Un angoissant problème de lemmatisation: le traitement du participle." En Pijnenburg, W. y Tollenaere, F. (eds.). Proceedings of the Second International Round Table Conference on Historical Lexicography. Dordrecht: Foris Publications, pp. 117-148.

Felíu Arquiola, E. (2008). "La codificación de los participios adjetivos activos.” En Rodríguez Espiñeira, M. ${ }^{a}$ J. y Pena, J. (eds.). Categorización lingüística y límites categoriales. Santiago de Compostela: Servicio de Publicacións, pp. 165-180.

Freixas, M. (2012). "El método lexicográfico de la Real Academia Española entre los años 1732-1770: las plantas de la segunda edición del Diccionario de autoridades (tomo I, A-B)." En Nomdedeu, A. et alii. (coords.). Avances de lexicografía hispánica. Tarragona: Universitat Rovira i Virgili, vol. I, págs. 301-315.

Freixas, M. y Clavería, G. (2018): "Los criterios de lematización: los lemas simples y los lemas múltiples", En Clavería, G. y Freixas, M. (coords.). El diccionario de la Academia en el siglo XIX: la $5^{a}$ edición (1817) al microscopio. Madrid: Arco Libros, pp. 93-102.

Gómez Asencio, J. J. (1981). Gramática y categorías verbales en la tradición española (1771-1847). Salamanca: Ediciones Universidad de Salamanca.

González Ollé, F. (2014). La Real Academia Española en su primer siglo. Madrid: Arco Libros.

Hernando Cuadrado, L. A. (2001). "Sobre la naturaleza léxico-gramatical del participio." En Veiga, A. et alii. (eds.). El verbo entre el léxico y la gramática. Lugo: Editorial Tris Tram, pp. 85-94.

Herrero Ruiz de Loizaga, F. J. (2006). "El paréntesis etimológico en el DRAE-2001.”, En Campos Souto, M. y Pérez Pascual, J. I. (eds.). El Diccionario de la Real Academia Española: ayer y hoy. Coruña: Universidade da Coruña, Anexos de la Revista de Lexicografía, pp. 155-166.

Jiménez Ríos, E. (1999). "La presencia de los participios pasivos en el Diccionario de la Academia", Hesperia. Anuario de Filología Hispánica, II, pp. 55-77.

Luque Durán, J. D. y Manjón Pozas. J. F. (1997). "Sobre la deriva semántica y funcional de los participios: análisis de algunos problemas previos a la descripción sistémica lexicográfica de las formas participiales del español.” En Luque Durán, J. D. y Pamies Bertrán, A. (eds.). Problemas de lexicología y lexicografía. Granada: Granada Lingüística y Método Ediciones, pp. 117-146.

Martín García, J. (2008). “Los participios adjetivos pasivos en los diccionarios del español.” En Rodríguez Espiñeira, M. ${ }^{a}$ J. y Pena. J. (eds.). Categorización lingüística y límites categoriales. Santiago de Compostela: Servicio de Publicacións, pp. 149-163.

Moliner, M. (1966-1967). Diccionario de uso del español. Madrid: Gredos.

$N T L L E=$ Real Academia Española (2001). Nuevo tesoro lexicográfico de la lengua española. Madrid: Espasa, edición en DVD. [<http://ntlle.rae.es $>]^{58}$.

Pena, J. (1994-1995). "Formación de palabras, gramática y diccionario", Revista de Lexicografía, 1, pp. 163-181.

58 Las ediciones del diccionario de la Academia, además del Diccionario de autoridades, el Vocabulario españollatino de Nebrija, el Tesoro de Covarrubias, los diccionarios de Domínguez, Gaspar y Roig, Núñez Taboada, Terreros, Salvá y Zerolo se citan por este tesoro lexicográfico. 
RAE-ASALE = Real Academia Española y Asociación de Academias de la Lengua Española (2009): Nueva gramática de la lengua española. Madrid: Espasa, 2 vols.

Seco, M. (1987). "Problemas formales de la definición", Estudios de lexicografía española. Madrid: Paraninfo, pp. 15-34.

Seco, M. (1991). "Introducción.” En Real Academia Española, Diccionario de la lengua castellana reducido a un tomo para su más fácil uso. Facsímil de la primera edición (1780). Madrid, iii-xii.

Seco, M. Andrés, O. y Ramos. G (2011). Diccionario del español actual. Madrid: Santillana Ediciones.

Werner, R. (1982). "La unidad léxica y el lema." En Haesnch, G. et alii. La lexicografía. Madrid: Gredos, pp. 188-232. 